\title{
Expressão das lodotironinas Desiodases nas Neoplasias Tireoidianas
}

\section{revisão}

\author{
ERIKA L. SOUZA MeYeR \\ MÁRCIA S. WAGNER \\ ANA LUIZA MAIA
}

Setor de Tireóide, Serviço de Endocrinologia do Hospital de

Clínicas de Porto Alegre,

Faculdade de Medicina,

Universidade Federal do Rio Grande do Sul, Porto Alegre, RS.

As iodotironinas desiodases formam uma família de selenoenzimas com propriedades catalíticas distintas que ativam ou inativam os hormônios tireoidianos via desiodação do anel fenólico ou tirosínico da molécula do T4. As desiodases tipo I e II (D1 e D2) são as enzimas responsáveis pela geração do T3 e são amplamente expressas na tireóide normal. A transformação neoplásica benigna ou maligna da glândula tireóide está associada a alterações na expressão dessas isoenzimas, sugerindo um possível papel da D1 e da D2 como marcadores de diferenciação celular. Anormalidades na expressão de ambas enzimas e da desiodase tipo III (D3), inativadora do hormônios tireoidianos, são também encontradas em outras neoplasias humanas. Os mecanismos ou implicações do aumento ou diminuição das desiodases na patogênese neoplásica são pouco compreendidas. No entanto, é importante observar que a expressão anormal da D2 pode ser responsável por um quadro de tireotoxicose em pacientes com metástases de carcinoma folicular de tireóide, enquanto que o aumento da D3 em hemangiomas pode causar hipotireoidismo de difícil tratamento. (Arq Bras Endcocrinol Metab 2007;51/5:690-700)

Descritores: lodotironinas desiodases; Neoplasias; Expressão gênica

\section{ABSTRACT}

lodothyronine Deiodinases Expression in Thyroid Neoplasias.

The iodothyronine deiodinases constitute a family of selenoenzymes that catalyze the removal of iodine from the outer ring or inner ring of the thyroid hormones. The activating enzymes, deiodinases type I (D1) and type II (D2), are highly expressed in normal thyroid gland. Benign or malignant neoplastic transformation of the thyroid cells is associated with changes on the expression of these enzymes, suggesting that D1 or D2 can be markers of cellular differentiation. Abnormalities on the expression of both enzymes and also of the deiodinase type III (D3), that inactivates thyroid hormones, have been found in other human neoplasias. So far, the mechanism or implications of these findings on tumor pathogenesis are not well understood. Nevertheless, it's noteworthy that abnormal expression of D2 can cause thyrotoxicosis in patients with metastasis of follicular thyroid carcinoma and that increased D3 expression in large hemangiomas causes severe hypothyroidism. (Arq Bras Endcocrinol Metab 2007;51/5:690-700)

Keywords: lodothyronine deiodinases; Neoplasia; Gene expression

$\mathrm{O}$ HORMÔNIO TIREOIDIANO É PRODUZIDO pela glândula tireóide na forma de um precursor inativo, a tiroxina $\left(3,5,3^{\prime}, 5^{\prime}\right.$ 'tetraiodo-Ltiroxina, T4). Em humanos, apenas $20 \%$ da forma biologicamente ativa do hormônio, a triiodotironina (3,5,3'-triiodo-L-tironina, T3), é secretada diretamente pela tireóide. Assim, a maior parte do T3 circulante é derivada 
da desiodação do anel externo da molécula de T4 nos tecidos periféricos, através da ação de enzimas denominadas iodotironinas desiodases (1).

O hormônio tireoidiano, dentre outras ações, estimula a diferenciação e proliferação celular. Alguns estudos indicam que, ao menos in vitro, os hormônios tireoidianos desempenhem um papel na transformação neoplásica induzida pela radiação ou por substâncias carcinógenas $(2,3)$. Outros estudos têm associado o status tireoidiano com a tumorigênese e o crescimento de tumores sólidos $(4,5)$. Uma das ações do T3 na proliferação de células neoplásicas foi documentada através de um estudo que demonstrou que concentrações fisiológicas de T3 bloqueiam a resposta transcricional sinalizada pela via RAS nas células de neuroblastoma (6). A repressão dos níveis de ciclina Dl, proteína envolvida na progressão do ciclo celular, pelo T3 parece ser um importante componente do mecanismo que bloqueia a proliferação celular ras-dependente. O T3 pode inibir a resposta oncogênica das 3 isoformas $\mathrm{N}$-, K- e H-RAS e ambos os receptores do hormônio tireoidiano (TR $\alpha$ e $\operatorname{TR} \beta)$ parecem mediar esta ação (6).

O envolvimento do T3 na gênese tumoral também foi demonstrado em estudos com camundongos transgênicos, nos quais uma mutação na isoforma do receptor do hormônio tireoidiano TR $\beta$ induziu a formação espontânea do carcinoma folicular da tireóide (7). Nesses animais, uma mutação no éxon 10 em que ocorre uma inserção C no códon 448 produzindo um frameshift de 14 aminoácidos da cadeia carboxiterminal do TR $\beta$, impede a ligação do T3 ao seu receptor e age como um fator de transcrição dominante negativo nos elementos responsivos ao $\mathrm{T} 3$ (TREs). Essa mutação poderia alterar a transcrição de vários genes regulados por esse hormônio e que podem estar envolvidos na proliferação e diferenciação celular. Com base nessas observações, o gene do TR $\beta$ é questionado como um possível gene supressor tumoral. É interessante observar que alguns estudos prévios demonstraram anormalidades na expressão dos TRs, tanto ao nível do RNA mensageiro quanto da proteína, sendo que mutações somáticas no $\mathrm{TR} \alpha$ e no TR $\beta$ foram identificadas em vários tumores humanos, tais como fígado, rim e tireóide (8-11).

Os carcinomas da tireóide constituem as neoplasias malignas mais freqüentes do sistema endócrino (12). Os carcinomas tireoidianos são classificados de acordo com o tipo histológico em papilar, folicular, medular e indiferenciado ou anaplásico, sendo que os carcinomas papilar e folicular, denominados carcinomas diferenciados, representam aproximadamente $85 \%$ dos casos (13). Os carcinomas diferenciados da tireóide na maioria das vezes mantêm as características bioquímicas da célula folicular normal. No entanto, várias anormalidades têm sido descritas na expressão gênica da tireoglobulina, da tireoperoxidase, do receptor do TSH e do co-transportador $\mathrm{Na}^{+} / \mathrm{I}^{-}$(14-16): proteínas responsáveis pela síntese dos hormônios da tireóide. A análise da expressão dessas proteínas em tecidos normais e neoplásicos da tireóide tem buscado a identificação de possíveis marcadores de diferenciação celular com implicações no diagnóstico, tratamento e prognóstico dos carcinomas diferenciados da tireóide (17-19).

Recentemente, o padrão de expressão das desiodases nos tecidos neoplásicos também passou a despertar interesse. Anormalidades na expressão dessas enzimas são encontradas nos tecidos tumorais, sendo que as alterações parecem ser específicas ao tipo histológico (20-25). Nas neoplasias tireoidianas, as desiodases têm sido questionadas como possíveis marcadores de diferenciação celular $(20,21)$. Atualmente aceita-se que é necessário um suprimento adequado de T3 intratecidual, combinado com a sinalização mediada pelos TRs, para a manutenção das características diferenciadas das células, a apoptose e a prevenção do crescimento de clones tumorigênicos (26). O objetivo dessa revisão é descrever o padrão de expressão das desiodases nas neoplasias da tireóide e nos demais tumores humanos, bem como discutir as possíveis implicações dessas alterações.

\section{NEOPLASIAS BENIGNAS E MALIGNAS DA GLÂNDULA TIREÓIDE: ASPECTOS MOLECULARES}

A célula epitelial folicular da tireóide é responsável pela biossíntese dos hormônios tireoidianos. Quatro tipos distintos de neoplasias tireoidianas se originam dessa célula: os adenomas foliculares e os carcinomas papilar, folicular e anaplásico (13). Mutações ativadoras no gene do receptor do TSH e da proteína G são as anormalidades genéticas associadas aos adenomas foliculares hiperfuncionantes $(27,28)$. A mutação no gene $B R A F(T 1799 A)$ parece ser a alteração genética mais freqüente nos carcinomas papilares, sendo que essa mutação não ocorre concomitante às alterações no RAS e RET/PTC, dois oncogenes também envolvidos na patogênese dos carcinomas diferenciados da tireóide $(29,30)$. Ainda no carcinoma papilar destacam-se os rearranjos do oncogene RET com genes heterólogos, dando origem ao gene quimérico RET/ PTC (31). Nos adenomas e carcinomas foli- 
culares, além das mutações ativadoras dos genes RAS, temos os rearranjos cromossomais entre o PAX-8, um fator de transcrição relevante para o desenvolvimento tireoidiano, e o receptor nuclear PPAR $\gamma$, que está envolvido no controle da proliferação e diferenciação celular $(32,33)$. Outras mutações de oncogenes e genes supressores tumorais contribuem para a desdiferenciação em carcinoma anaplásico (p53, Rb) (34). Uma leitura mais detalhada sobre a genética molecular dos carcinomas diferenciados da tireóide pode ser revista no artigo de Maciel e cols. (35).

\section{IODOTIRONINAS DESIODASES}

Os hormônios tireoidianos são pequenas moléculas ligantes hidrofóbicas não-peptídicas essenciais para vários processos biológicos como desenvolvimento, crescimento, diferenciação e metabolismo (36,37). Sua ação ocorre, fundamentalmente, através da ligação do hormônio a receptores nucleares (TRs) localizados em seqüências específicas, os elementos responsivos ao hormônio tireoidiano (TREs), na região promotora dos genes-alvo. A formação do complexo hormônioreceptor resulta em alterações na composição do complexo transcricional e este processo pode tanto aumentar quanto reprimir a transcrição (38).

O T4, principal produto secretado pela tireóide, funciona primariamente como um pró-hormônio, sendo transformado no hormônio biologicamente ativo, o T3, que possui alta afinidade pelos TRs (39). As iodotironinas desiodases tipos I (D1), II (D2) e III (D3) formam uma família de selenoenzimas que, com propriedades catalíticas distintas, ativam ou inativam o hormônio tireoidiano via desiodação do anel fenólico ou tirosínico das iodotironinas (figura 1) (40). Embora as três desiodases apresentem em comum certas características estruturais importantes, essas enzimas diferem entre si em vários aspectos como no pa-

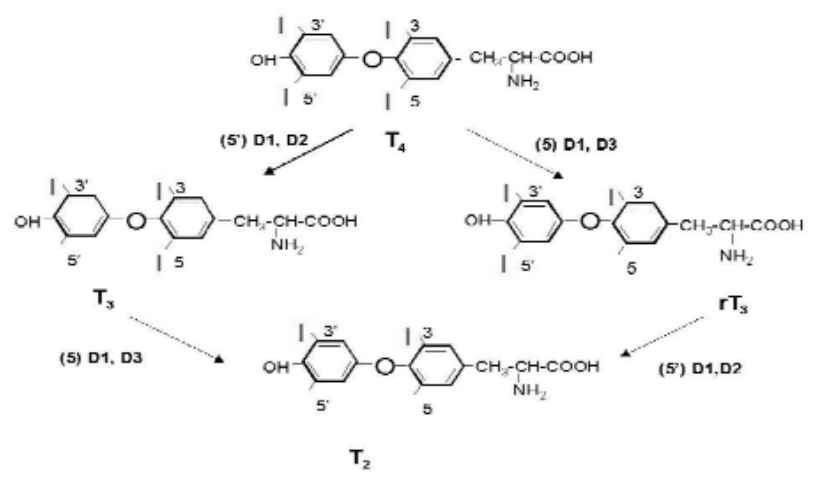

Figura 1. Produtos da monodesiodação do T4. drão de expressão tecidual, localização celular, papel fisiológico, preferência pelo substrato, sensibilidade a inibidores e na forma como são reguladas pelos hormônios tireoidianos. A tabela 1 sumariza as principais características das três desiodases humanas.

A atividade das desiodases é regulada por um processo complexo, e vários fatores e/ou situações fisiopatológicas podem alterar a desiodação em um determinado tecido (1). De fundamental importância regulatória são as alterações no status dos hormônios tireoidianos, que determinam mudanças significativas na atividade das desiodases. Do ponto de vista fisiológico, estas mudanças parecem coordenadas de forma a manter os níveis circulantes e intracelulares de T3 próximos do normal. Além de serem expressas em vários tecidos periféricos, as isoenzimas D1 e D2 são amplamente encontradas na tireóide, especialmente na célula folicular $(41,42)$. Aproximadamente 30 a $50 \%$ do T3 secretado diretamente pela tireóide deriva da desiodação intratireoidiana do T4 (42).

\section{DESIODASE TIPO 1}

Em humanos, os níveis mais elevados de expressão da Dl são encontrados no fígado, rim, tireóide e hipófise (1). A Dl apresenta uma característica única entre as desiodases, pois pode catalisar a desiodação tanto do anel fenólico quanto do anel tirosínico das diversas iodotironinas, e esses processos resultam, respectivamente, na ativação e inativação dos hormônios tireoidianos (figura 1). Nos mamíferos em geral, a atividade da Dl, particularmente da Dl hepática, é considerada uma importante fonte de T3 plasmático no estado eutireóideo $(1,43)$. Em humanos, apesar da Dl contribuir na produção do T3 plasmático, sua contribuição mais significativa ocorre nos pacientes com hipertireoidismo (44). Além de atuar na ativação do T4, a Dl também participa no rápido clearence do rT3 e na inativação das iodotironinas sulfatadas (45). A expressão da Dl é regulada ao nível transcricional pelo hormônio tireoidiano. Vários estudos demonstraram que o T3 estimula a síntese da Dl através de um efeito direto sobre a taxa de transcrição gênica da enzima, induzindo aumentos nos níveis do RNA mensageiro e, conseqüentemente, da proteína (46). De fato, dois TREs funcionais foram identificados no promotor do gene da Dl humano $(47,48)$. Em particular na tireóide, a expressão da Dl é estimulada via TSH/AMP cíclico (AMPc) (49).

\section{Expressão da D1 nas neoplasias tireoidianas}

Vários estudos avaliaram a expressão da Dl nas neoplasias tireoidianas. Khörle e cols. (20) demonstraram 
Tabela 1. Principais características das iodotironinas desiodases.

\begin{tabular}{|c|c|c|c|}
\hline Características & D1 & D2 & D3 \\
\hline Localização do gene & Cr. 1p32-p33 & Cr. $14 q 24.3$ & Cr. $14 q 32$ \\
\hline Peso molecular (kDa) & 27 & 30 & 31 \\
\hline Papel fisiológico & $\begin{array}{c}\text { Fornece T3 para } \\
\text { o plasma }\end{array}$ & $\begin{array}{l}\text { Fornece T3 para o } \\
\text { espaço intracelular }\end{array}$ & Inativa T3 e T4 \\
\hline Localização & Fígado, rim, tireóide & $\begin{array}{l}\text { Hipófise, cérebro, } \\
\text { tecido adiposo } \\
\text { marrom, placenta, } \\
\text { tireóide, músculos } \\
\text { cardíaco e esquelético }\end{array}$ & $\begin{array}{c}\text { Útero, placenta, tecidos } \\
\text { fetais, pele, cérebro } \\
\text { e hipófise }\end{array}$ \\
\hline $\begin{array}{l}\text { Preferência pelo } \\
\text { substrato }\end{array}$ & $r T 3>>T 4>T 3$ & $\mathrm{~T} 4>\mathrm{T} 3$ & $\mathrm{~T} 3>\mathrm{T} 4$ \\
\hline Sítio de desiodação & $\begin{array}{l}\text { Anel interno e } \\
\text { externo }\end{array}$ & Anel externo & Anel interno \\
\hline $\begin{array}{l}\text { Sensibilidade ao } \\
\text { propiltiouracil (PTU) }\end{array}$ & Sensível & Resistente & Resistente \\
\hline $\begin{array}{l}\text { Efeito dos hormônios } \\
\text { tireoidianos na } \\
\text { atividade }\end{array}$ & Aumenta & Diminui & Aumenta \\
\hline
\end{tabular}

uma variabilidade nos níveis de expressão da Dl em 10 amostras não-pareadas de carcinoma papilar, sendo que foram observados desde níveis indetectáveis até níveis muito altos de expressão. Por outro lado, Toyoda e cols. (50) observaram uma redução da proteína de $27 \mathrm{kDa}$ com propriedades da Dl, em 4 de 5 casos de carcinoma papilar. Em trabalho realizado pelo nosso grupo, observamos uma significativa redução nos níveis de RNA mensageiro e atividade da Dl em todas as 14 amostras de carcinoma papilar avaliadas (24). Esses resultados foram observados em todos os subtipos histológicos, que incluíam desde as formas clássica, variante folicular, variante esclerosante difusa até microcarcinomas; e nos diferentes estágios clínicos (figura 2a, b). Em acordo com os nossos resultados, Arnaldi e cols. (25) também descreveram uma redução nos níveis de RNA mensageiro da Dl nos carcinomas papilares.

Em contraste com a significativa redução da Dl nos carcinomas papilares, nos adenomas e carcinomas foliculares da tireóide, os níveis da Dl estão aumentados em relação ao tecido normal (figura 3a, b, c) (24). Achados semelhantes foram detectados em amostra de carcinoma de células de Hürthle (24). A análise desses resultados parece indicar que a desdiferenciação celular da tireóide promove alterações na expressão gênica da Dl através de mecanismos pré-transcricionais, um evento específico na progressão para o carcinoma papilar.

Atividade da Dl também foi descrita no carcinoma anaplásico. Estudos prévios relataram níveis muito baixos ou indetectáveis nesse tipo de carcinoma, com resultados similares em linhagens celulares correspondentes $(20,51)$. No entanto, nós detectamos níveis elevados de atividade em 1 amostra de carcinoma anaplásico misto (24). Com base nos achados da expressão da Dl nos carcinomas papilares e foliculares, esses resultados aparentemente conflitantes podem, talvez, sugerir o tipo histológico a partir do qual ocorreu a desdiferenciação tumoral (52).

Alterações na regulação da Dl também foram documentadas nas células tireoidianas neoplásicas. Nos estudos realizados em linhagens de células humanas de carcinoma folicular de tireóide (FTC 133 e FTC 238), observou-se que a Dl perde a resposta ao estímulo fisiológico do TSH e do T3, mas mantém-se sensível ao ácido retinóico, um metabólito ativo da vitamina $\mathrm{A}$ que regula a taxa de crescimento e diferenciação de vários tipos celulares (51). Nessas células, $\mathrm{o}$ ácido retinóico estimula a atividade da Dl em 5 a 10 vezes. Nas linhagens humanas menos diferenciadas, ocorre também uma perda da resposta ao ácido retinóico (51).

\section{Expressão da D1 em outras neoplasias}

No carcinoma de células claras, o tipo mais freqüente de carcinoma renal, foram descritos níveis indetectáveis de RNA mensageiro e atividade da Dl em todas as 10 amostras analisadas (53). Os autores especulam que a perda da expressão da Dl seja em conseqüência da transformação neoplásica ou que a célula-origem desse tumor seja tubular, que normalmente não expressa essa enzima. A redução na expressão da Dl tam- 
A

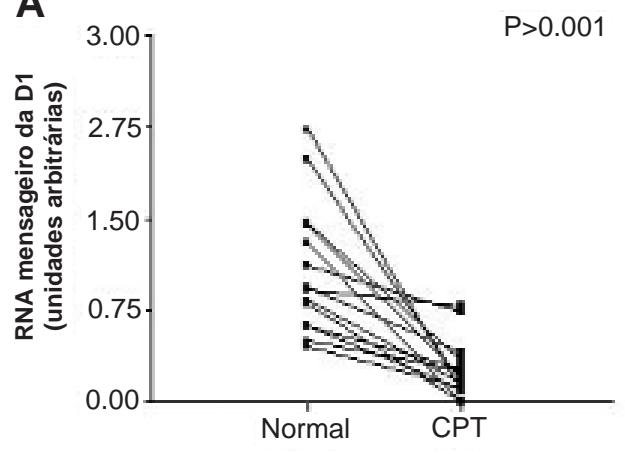

B

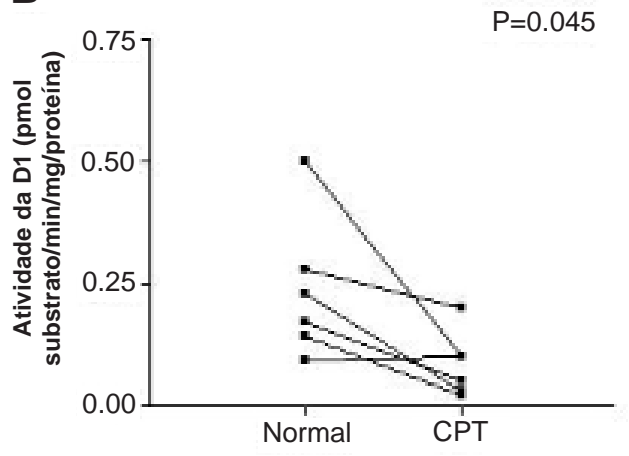

Figura 2. (a) Níveis de RNA mensageiro da D1 em unidades arbitrárias no carcinoma papilar da tireóide (CPT) e tecido normal adjacente. (b) Atividade enzimática da D1 no CPT e tecido normal adjacente. A atividade da D1 foi realizada utilizando $1 \mu \mathrm{M}$ de T4 como substrato. [Adaptada da ref. 24]
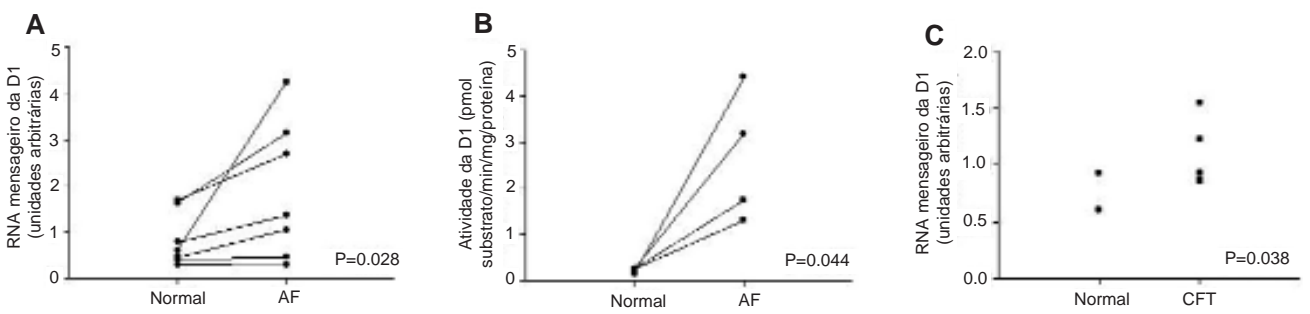

Figura 3. (a) Níveis de RNA mensageiro da D1 em unidades arbitrárias no adenoma folicular da tireóide (AF) e tecido normal adjacente. (b) Atividade enzimática da D1 no AF e tecido normal adjacente. A atividade da D1 foi realizada utilizando $1 \mu \mathrm{M}$ de T4 como substrato. (c) Níveis de RNA mensageiro da D1 em unidades arbitrárias no carcinoma folicular da tireóide (CFT) e tecido normal. [Adaptada da ref. 24]

bém foi demonstrada em amostras de adenocarcinoma de fígado comparada ao tecido normal (54), sendo que nas células derivadas de carcinoma hepatocelular humano (Hep G2), um aumento de 2 vezes na atividade da Dl foi descrito com o uso do ácido retinóico (51). A atividade da Dl também está significativamente reduzida no adenocarcinoma e carcinoma pulmonar de células escamosas (55). Achados semelhantes foram descritos no câncer de próstata (56).

Um resultado conflitante ao que foi evidenciado na maioria das neoplasias humanas, nas quais observamos uma hipoexpressão da Dl, foi descrito em carcinoma de glândula mamária de ratas Sprague-Dawley induzido por N-metil-N-nitrouréia (MNU), em que a atividade enzimática da Dl estava pelo menos 2 vezes mais alta do que no tecido mamário normal não-lactante (57). No entanto, os níveis da Dl eram maiores nos tumores com 2 a 4 meses do que nos tumores com mais de 6 meses de crescimento (58), caracterizando uma perda da expressão da Dl com a evolução tumoral. Na glândula mamária de ratos, a Dl está aumentada na lactação, principalmente no epitélio alveolar, e sua expressão é regulada pela sucção através do estímulo $\beta$-adrenérgico (59).
Em relação à regulação da $\mathrm{Dl}$ nas células neoplásicas, foi demonstrado que nas células MCF-7, uma linhagem celular humana de carcinoma de mama ovariano-dependente, a Dl responde ao ácido retinóico, enquanto que está abolida a regulação pelo T3 e pelo agonista $\beta$-adrenérgico isoproterenol (60). Similarmente ao que ocorre em outras linhagens celulares neoplásicas, na linhagem menos diferenciada de carcinoma de mama (MDA-MB-231) não foi encontrada atividade da Dl, tanto nas condições basais ou em tratamentos (60). Esses resultados reforçam a possibilidade de a Dl ser um marcador de desdiferenciação celular como sugerido em outros estudos $(20,21)$.

Ao contrário do sistema nervoso central (SNC) de ratos, nenhuma atividade da Dl foi documentada no SNC de humanos (61). No entanto, alguns estudos demonstraram que a Dl está presente tanto na hipófise normal quanto nos adenomas hipofisários humanos $(62,63)$. Níveis muito baixos de RNA mensageiro da Dl, quase próximos ao limite da detecção do método, foram descritos em $50 \%$ das amostras de pituitária normal e tumoral. Outro estudo detectou atividade da Dl tanto na hipófise normal quanto nos adenomas hipo- 
fisários, sendo que níveis elevados de atividade da Dl foram descritos em algumas amostras de tecido normal e de tumores não-funcionantes ou produtores de prolactina (63). A tabela 2 sumariza os principais achados sobre a expressão da Dl nas neoplasias humanas.

\section{DESIODASE TIPO 2}

A D2 é uma enzima que catalisa exclusivamente a desiodação do anel externo das iodotironinas desempenhando um papel crítico na ativação do $\mathrm{T} 4 \mathrm{em}$ diferentes tecidos. Em humanos, o RNA mensageiro e/ou a atividade da D2 estão presentes principalmente no cérebro, hipófise, tireóide, placenta e músculos cardíaco e esquelético (1). Embora o principal papel fisiológico atribuído à D2 seja a produção intracelular de T3, estudos recentes sugerem que a D2 presente no músculo esquelético contribui com uma parcela significativa da produção do T3 plasmático em humanos (44).

Em geral, a atividade da D2 apresenta uma correlação inversa com os níveis séricos dos hormônios tireoidianos, estando aumentada no hipotireoidismo e diminuída no hipertireoidismo (64). Mecanismos pré e pós-transcricionais estão envolvidos na regulação da expressão da D2 pelos hormônios tireoidianos com papéis distintos para o T3, T4 e rT3. O T3 atua principalmente ao nível transcricional diminuindo os níveis de RNA mensageiro da D2, enquanto o T4 e o rT3 rapidamente reduzem a atividade enzimática póstranscricionalmente, aumentando a taxa de ubiquitinação e posterior degradação da enzima via proteossomas (65). Vários fatores parecem capazes de modular a taxa de transcrição do gene da D2, como o AMPc, os fatores de transcrição TTF-1 e PAX-8, a proteína ativadora 1 (APl) e agentes adrenérgicos (66). Na tireóide, a expressão da D2 está relacionada ao grau de estímulo tecidual via TSH/AMPc, com aumento da expressão encontrado na Doença de Graves e nos adenomas hiperfuncionantes (41).

\section{Expressão da D2 nas neoplasias tireoidianas}

No carcinoma papilar da tireóide foi descrita uma redução nos níveis de RNA mensageiro e na atividade enzimática da $\mathrm{D} 2$, um processo que, segundo os autores, pode ser secundário à transformação neoplásica (23). Um dado interessante é que nas variantes foliculares dessa neoplasia, não se observa uma redução significativa nos níveis de expressão da enzima em relação ao tecido tireoidiano normal (25).

Tabela 2. Padrão de expressão das iodotironinas desiodases nas neoplasias humanas em geral.

\begin{tabular}{|c|c|c|c|c|c|c|c|}
\hline \multirow[t]{2}{*}{ Tipo de tumor } & \multicolumn{2}{|c|}{ D1 } & \multicolumn{2}{|c|}{ D2 } & \multicolumn{2}{|c|}{ D3 } & \multirow[t]{2}{*}{ Refs. } \\
\hline & RNAm & Atividade & RNAm & Atividade & RNAm & Atividade & \\
\hline $\begin{array}{l}\text { Carcinoma papilar } \\
\text { da tireóide }\end{array}$ & Diminuído & Diminuída & Diminuído & Diminuída & N/A & $N / A$ & $(23-25)$ \\
\hline $\begin{array}{l}\text { Carcinoma } \\
\text { folicular da } \\
\text { tireóide }\end{array}$ & $\begin{array}{l}\text { Normal ou } \\
\text { aumentado }\end{array}$ & Aumentada & $\begin{array}{l}\text { Normal ou } \\
\text { aumentado }\end{array}$ & Aumentada & $N / A$ & $N / A$ & $(24,25)$ \\
\hline $\begin{array}{l}\text { Carcinoma renal } \\
\text { de células claras }\end{array}$ & $\begin{array}{l}\text { Diminuído ou } \\
\text { indetectável }\end{array}$ & $\begin{array}{l}\text { Diminuída ou } \\
\text { indetectável }\end{array}$ & $N / A$ & $N / A$ & $N / A$ & $N / A$ & (53) \\
\hline $\begin{array}{l}\text { Adenocarcinoma } \\
\text { de fígado }\end{array}$ & $N / A$ & Diminuída & $\mathrm{N} / \mathrm{A}$ & $\mathrm{N} / \mathrm{A}$ & $N / A$ & $\mathrm{~N} / \mathrm{A}$ & (54) \\
\hline $\begin{array}{l}\text { Adenocarcinoma e } \\
\text { carcinoma de células } \\
\text { escamosas de pulmão }\end{array}$ & N/A & Diminuída & N/A & Inalterada & N/A & N/A & (55) \\
\hline $\begin{array}{l}\text { Carcinoma de } \\
\text { próstata }\end{array}$ & & iminuição da $5^{\prime}$ & desiodação & & $N / A$ & $N / A$ & (56) \\
\hline Carcinoma de mama & $\mathrm{N} / \mathrm{A}$ & Diminuída & $N / A$ & $N / A$ & $N / A$ & $N / A$ & (59) \\
\hline Adenoma de hipófise & Diminuído & Diminuída* & Aumentado & Aumentada & Aumentado & Inalterada** & $(62,63)$ \\
\hline Mesotelioma & $\mathrm{N} / \mathrm{A}$ & $\mathrm{N} / \mathrm{A}$ & Aumentado & Aumentada & $\mathrm{N} / \mathrm{A}$ & $\mathrm{N} / \mathrm{A}$ & (78) \\
\hline Osteossarcoma & $\mathrm{N} / \mathrm{A}$ & $N / A$ & Diminuído & Diminuída & $\mathrm{N} / \mathrm{A}$ & N/A & (79) \\
\hline Hemangioma & $\mathrm{N} / \mathrm{A}$ & $N / A$ & $\mathrm{~N} / \mathrm{A}$ & $\mathrm{N} / \mathrm{A}$ & Aumentado & Aumentada & $(85,86)$ \\
\hline
\end{tabular}

\footnotetext{
N/A: não avaliado

* detectável em 1 amostra de 16 adenomas não-funcionantes

** detectável em 3 amostras de 16 adenomas não-funcionantes
} 
Semelhante ao que foi observado na expressão da Dl nas lesões foliculares, os níveis de RNA mensageiro da D2 nos adenomas e carcinomas foliculares são similares ao tecido não-neoplásico (25), enquanto que nos adenomas foliculares hiperfuncionantes é observada uma alta expressão da D2 (41). É interessante no entanto que, em metástases de carcinoma folicular foram descritos altos níveis de atividade da D2 que determinavam um persistente aumento da relação sérica de T3/T4 nos pacientes $(24,67,68)$. Em conseqüência do aumento da atividade da D2 no tumor, pacientes com grandes e/ou múltiplas metástases de carcinoma folicular podem apresentar um quadro clínico de T3-tireotoxicose devido ao aumento da conversão do T4 exógeno pelo tecido tumoral (68).

\section{Expressão da D2 em outras neoplasias}

A D2 está normalmente expressa no tecido cerebral humano, sendo que em neoplasias cerebrais foram identificados receptores dos hormônios tireoidianos, indicando um possível envolvimento desses hormônios na proliferação celular desse tipo tumoral $(61,69,70)$. A atividade da D2 foi identificada em astrocitomas, glioblastomas e oligodrendrogliomas, com forte correlação com os seus níveis de RNA mensageiro, sugerindo uma regulação pré-transcricional da expressão dessa enzima nos tumores cerebrais (71). Os maiores níveis de atividade foram encontrados nos gliosarcomas (72). Por outro lado, nenhuma atividade de desiodação do T4 foi detectada nos meningiomas, sendo a explicação mais provável a diferença na origem embriológica desses tumores (células da aracnóide), em contraste aos gliomas que se originam das células gliais (73).

Além do seu papel na regulação da secreção de TSH através do feedback negativo, os hormônios tireoidianos parecem estar envolvidos na regulação do crescimento e diferenciação da célula hipofisária $(74,75)$. Com exceção dos tumores hipofisários secretores de ACTH e TSH, os demais tumores hipofisários apresentam um aumento significativo nos níveis de RNA mensageiro e atividade da D2 quando comparados com a pituitária normal (62). A maior atividade da D2 parece ocorrer nos subtipos produtores de TSH e prolactina, quando comparados aos tumores nãofuncionantes, aos produtores de GH e ACTH (63). Segundo os autores, esses resultados demonstram que apesar da transformação tumoral, a D2 permanece ativa, mantendo o seu papel na função e regulação da hipófise anterior humana.

Várias linhagens celulares tumorais humanas apresentam atividade da D2. As células JEG3, uma linhagem de coriocarcinoma humano, mantêm a ex- pressão da D2 apesar da transformação tumoral e sua responsividade ao tratamento com $\operatorname{AMPc}(76)$. Foi demonstrado que as células MSTO-211H, uma linhagem de mesotelioma humano, expressam o gene da D2, apresentando níveis de RNA mensageiro 40 vezes mais elevados do que as células mesoteliais normais $(77,78)$. Uma alta atividade da D2 foi encontrada nessas células, sendo aproximadamente $40 \%$ maior do que a encontrada em tecidos de pacientes com Doença de Graves (78). A D2 também foi identificada em células de osteossarcoma humano (SaOS-2), embora com expressão mais baixa em relação às células osteoblásticas normais (NHOst) (79). Nessas células, tanto os níveis de RNA mensageiro quanto a atividade enzimática rapidamente aumentam sob o estímulo do TSH. Além disso, as 3 isoformas de receptores do T3 foram encontradas, sugerindo um possível papel do T3 gerado localmente pela D2 na maturação e remodelamento do osso normal. A presença da D2 também foi descrita em carcinomas de pulmão, similares ao tecido circunjacente (55). A tabela 2 sumariza os principais achados sobre a expressão da D2 nas neoplasias humanas.

\section{DESIODASE TIPO 3}

A D3 catalisa unicamente a desiodação do anel interno das moléculas de T4 e T3, resultando na formação dos metabólitos inativos rT3 e T2, respectivamente (figura 1). Os mais altos níveis de expressão da D3 são encontrados em tecidos fetais humanos e de roedores, na placenta, útero gravídico e vasos umbilicais $(80,81)$. Na vida adulta, a D3 está expressa predominantemente no sistema nervoso central e pele $(61,82)$. A atividade da D3 não foi detectada na tireóide em nenhum estágio do desenvolvimento ou na vida adulta. $\mathrm{O}$ alto nível de expressão nos tecidos fetais, placenta e útero sugere que a D3 regule os níveis circulantes e teciduais do T3 de modo a proteger o feto em desenvolvimento de uma indevida exposição ao hormônio tireoidiano ativo (80). No cérebro e pele de diferentes espécies, a atividade e os níveis de mRNA da D3 estão aumentados no hipertireoidismo e diminuídos no hipotireoidismo, entretanto os mecanismos envolvidos nesta regulação ainda não foram determinados (83). Não existem dados na literatura sobre a expressão da D3 nos tumores tireoidianos.

\section{Expressão da D3 em outras neoplasias}

A existência de atividade da D3 no cérebro humano adulto parece ser responsável pela inativação dos hor- 
mônios tireoidianos no sistema nervoso central $(61,73)$. Nauman e cols. (72) determinaram a concentração celular de T4 e T3 e a atividade enzimática em tecidos de gliomas humanos com vários graus de malignidade e em tecidos cerebrais normais. A atividade da D3 estava aumentada em todos os casos de gliossarcoma, em 9 de 10 casos de glioblastoma multiforme; e diminuída em todas as amostras de astrocitoma grau II e grau III quando comparada com a baixa atividade desta enzima encontrada no tecido cerebral normal. Os autores sugerem que essas alterações podem estar relacionadas com a progressão maligna.

Estudos prévios não identificaram a expressão da D3 em linhagem celular derivada da hipófise anterior humana (84). No entanto, a análise de adenomas hipofisários demonstrou níveis de RNA mensageiro aproximadamente 7 vezes mais elevados do que no tecido hipofisário normal. Maior expressão foi encontrada nos tumores secretores de TSH (13 vezes), seguidos pelos produtores de ACTH (7 vezes), nãofuncionantes (7 vezes) e pelos produtores de $\mathrm{GH}$ (6 vezes). No entanto, a atividade enzimática foi detectada somente em 3 de 16 tumores (18\%), todos nãofuncionantes (62).

A presença da D3 é relatada em anormalidades vasculares e em algumas linhagens de células malignas $(83,85,86)$. Dados recentes indicam que a expressão dessa enzima pode ser reativada após o nascimento em tecidos normais durante enfermidades críticas e outras condições patológicas (87). Recentemente, o RNA mensageiro e a atividade da D3 foram identificados em hemangiomas infantis em níveis 7 vezes maiores do que na placenta, um órgão que normalmente expressa uma grande quantidade dessa enzima. Como a D3 inativa os hormônios tireoidianos, o crescimento tumoral ou a presença de grandes hemangiomas pode provocar hipotireoidismo severo e de difícil tratamento (85). O primeiro caso relatado foi de uma criança de 3 meses de idade com vários hemangiomas hepáticos e hipotireoidismo primário refratário a altas doses de Ltiroxina para restabelecimento do eutireoidismo e da secreção normal de tireotrofina (TSH). Os altos níveis de atividade da D3 no tumor determinam uma maior degradação dos hormônios tireoidianos, sendo que o hipotireoidismo resolve com a ressecção ou involução do tumor. Os hemangiomas cutâneos também podem expressar níveis elevados de D3 (87). Nos adultos, a atividade aumentada de D3 em hemangiomas pode ser causa de hipotireoidismo subclínico (86). Dessa forma, uma alta suspeição para hipotireoidismo devese ter em crianças e adultos com grandes tumores vasculares.
Na busca de um maior entendimento do papel da D3 na regulação dos hormônios tireoidianos, alguns estudos têm avaliado a expressão dessa enzima em diferentes linhagens celulares humanas. A atividade e o RNA mensageiro da D3 estão presentes e fortemente correlacionados nas células de carcinoma de endométrio (ECC1), carcinoma de mama (MCF-7) e de neuroblastoma (SH-SY5Y) (83). A presença da atividade da D3 nas células MCF-7, segundo os autores, pode indicar que essa enzima pode estar expressa no tecido mamário somente em certas situações fisiológicas, tais como no período de lactação. Os estudos regulatórios demonstraram que o estradiol aumentou a atividade da D3 somente nas células ECC-1, sugerindo uma contribuição desse hormônio na indução da D3 no útero gravídico. Além disso, a incubação com ácido retinóico determinou o aumento em 2 a 3 vezes na atividade da D3 nos tipos ECC-1 e MCF-7, mas redução nas células SH-SY5Y, demonstrando com esses resultados uma regulação específica conforme o tipo celular. A expressão da D3 não foi afetada pelos hormônios tireoidianos ou pelo AMPc em nenhum tipo celular (83). Esses resultados caracterizam a perda do estímulo fisiológico dos hormônios tireoidianos em decorrência do processo neoplásico. A tabela 2 sumariza os principais achados sobre a expressão da D3 nas neoplasias humanas.

\section{CONSIDERAÇÕES FINAIS}

Em tumores humanos de origem epitelial provenientes de tecidos que normalmente expressam a Dl, geralmente ocorre uma redução na expressão dessa enzima no tecido neoplásico. No entanto, a expressão da D2 encontra-se inalterada ou mesmo aumentada, com exceção do carcinoma papilar da tireóide. Uma possível explicação, embora especulativa, é que a redução da expressão da Dl nos tumores possa decorrer da perda da resposta fisiológica ao T3. Já o mecanismo para as alterações na expressão da D2 parece ser mais complexo, em função de essa enzima apresentar regulação pré e pós-transcricional. De qualquer modo, é necessário determinar se as anormalidades na expressão das desiodases, principalmente da D2, são simplesmente uma conseqüência da transformação celular ou parte do processo de patogênese tumoral. Futuros estudos funcionais dessas enzimas em células tumorais auxiliarão no entendimento dessa questão. Até o momento, as repercussões da expressão anormal das desiodases nos tumores humanos são evidentes em metástases de carcinoma folicular da tireóide e em tumores de origem vascular. 


\section{REFERÊNCIAS}

1. Bianco AC, Salvatore D, Gereben B, Berry MJ, Larsen PR. Biochemistry, cellular and molecular biology, and physiological roles of the iodothyronine selenodeiodinases. Endocr Rev 2002;23:38-89.

2. Borek C, Guernsey DL, Ong A, Endelman IS. Critical role played by thyroid hormone in induction of neoplastic transformation by chemical carcinogens in tissue culture. Proc Natl Acad Sci USA 1983;80:5749-52.

3. Guernsey DL, Borek C, Edelman IS. Crucial role of thyroid hormone in X-ray-induced neoplastic transformation in cell culture. Proc Natl Acad Sci USA 1981;78:5708-11.

4. Lemaire M, Bayens W, de Saint-Georges L, Baugnet-Mahieu $\mathrm{L}$. Thyroid hormone influence on the growth of hepatoma HW-165 in Wistar rats. Biomedicine 1981;34:133-9.

5. Leuthauser SWC, Guernsey DL. Thyroid hormone affects the expression of neoplastic transformation induced by DNAtransfection. Cancer Lett 1987;35:321-6.

6. Garcia-Silva S, Aranda A. The thyroid hormone receptor is a suppressor of ras-mediated transcription, proliferation and transformation. Mol Cell Biol 2004;24:7514-23.

7. Kato $\mathrm{Y}$, Ying $\mathrm{H}$, Willingham MC, Cheng S-Y. A tumor suppressor role for thyroid hormone $\beta$ receptor in a mouse model of thyroid carcinogenesis. Endocrinology 2004; $145: 4430-8$.

8. Lin $\mathrm{KH}$, Shieh HY, Chen SL, Hsu HC. Expression of mutant thyroid hormone nuclear receptors in human hepatocellular carcinoma cells. Mol Carcinog 1999;26:53-61.

9. Kamiya $Y$, Puzianowska-Kuznicka M, McPhie P, Nauman J Cheng SY, Nauman A. Expression of mutant thyroid hormone nuclear receptors is associated with renal cell carcinoma. Carcinogenesis 2002;23:25-33.

10. Puzianowska-Kuznicka M, Krystyniak A, Madej A, Cheng SY, Nauman J. Functionally impaired TR mutants are present in thyroid papillary cancer. J Clin Endocrinol Metab 2002;87:1120-8.

11. Cheng SY. Thyroid hormone receptor mutations in cancer. Mol Cel Endocrinol 2003;213:23-30.

12. Schlumberger M, Pacini F. Thyroid tumors. Paris: Éditions Nucléon, 2003

13. Hedinger C, Williams ED, Sobin LH. Histological typing of thyroid tumours. International histological classification of tumors. World Health Organization, vol. 11, Second Edition, Springer-Verlag, Berlin, 1988

14. Tanaka K, Otsuki T, Sonoo H, Yamamoto $Y$, Udagawa K,

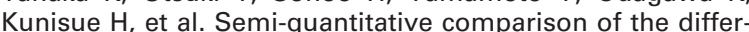
entiation markers and sodium iodide symporter messenger ribonucleic acids in papillary thyroid carcinomas using RTPCR. Eur J Endocrinol 2000;142:340-6.

15. Arturi F, Russo D, Bidart JM, Scarpelli D, Schlumberger M, Filetti S. Expression pattern of the pendrin and sodium/iodide symporter genes in human thyroid carcinoma cell lines and human thyroid tumors. Eur $\mathbf{J}$ Endocrinol 2001;145:129-35.

16. Gerard AC, Daumerie C, Mestdagh C, Gohy S, De Burbure C, Costagliola $S$, et al. Correlation between the loss of thyroglobulin iodination and the expression of thyroid-specific proteins involved in iodine metabolism in thyroid carcinomas. J Clin Endocrinol Metab 2003;88:4977-83.

17. Savin S, Cvejic D, Isic T, Petrovic I, Paunovic I, Tatic S, et al. Thyroid peroxidase immunohistochemistry in differential diagnosis of thyroid tumors. Endocr Pathol 2006;17:53-60.

18. Spitzweg C, Morris JC. The sodium iodide symporter: its pathophysiological and therapeutic implications. Clin Endocrinol 2002;57:559-74.

19. Mirebeau-Prunier D, Guyetant S, Rodien P, Franc B, Baris O, Rohmer V, et al. Decreased expression of thyrotropin receptor gene suggests a high-risk subgroup for oncocytic adenoma. Eur J Endocrinol 2004;150:269-76.

20. Khörle J, Oertel M, Hoang-Vu C, Schnieders F, Brabant G. Type I 5'-deiodinase - a marker for differentiated thyroid carcinoma? Exp Clin Endocrinol 1993;101:60-72.
21. Khörle J. Thyroid carcinoma: interrelationships between local thyroid metabolism by the type I $5^{\prime}$-deiodinase and the expression of thyroid hormone receptors and other thyroid specific (de)differentiation markers. Curr Top Pathol 1997;91:83-116.

22. Huang $Y$, Prasad M, Lemon WJ, Hampel H, Wright FA, Kornacker $\mathrm{K}$, et al. Gene expression in papillary thyroid carcinoma reveals highly consistent profiles. Proc Natl Acad Sci USA 2001;98:15004-49.

23. Murakami M, Araki O, Hosoi $Y$, Kamiya $Y$, Morimura T, Ogiwara $T$, et al. Expression and regulation of type II iodothyronine deiodinase in human thyroid gland. Endocrinology 2001: 142:2961-7.

24. Souza Meyer EL, Dora JM, Wagner MS, Maia AL. Decreased type 1 iodothyronine deiodinase expression might be an early and discrete event in thyroid cell dedifferentiation towards papillary carcinoma. Clin Endocrinol 2005:62:672-8.

25. Arnaldi LAT, Borra RC, Maciel RMB, Cerutti JM. Gene expression profiles reveal that $D C N, D I O 1$, and DIO2 are underexpressed in benign and malignant thyroid tumors. Thyroid 2005;15:210-21.

26. Khörle J. Guard your master: thyroid hormones receptors protect their gland of origin from thyroid cancer. Endocrinology 2004;145:4427-9.

27. Parma J, Duprez L, Van Sande J, Hermans J, Rocmans J, Van Vliet G, et al. Diversity and prevalence of somatic mutations in the thyrotropin receptor and Gs $\alpha$ genes as a cause of toxic thyroid adenomas. J Clin Endocrinol Metab 1997;82:2695-701.

28. Paschke R, Krohn K. Clinical review 133 - Progress in understanding the etiology of thyroid autonomy. $J$ Clin Endocrinol Metab 2001;86:3336-45.

29. Kimura ET, Nikiforova MN, Zhu Z, Knauf JA, Nikiforov YE, Fagin JA. High prevalence of BRAF mutations in thyroid cancer: genetic evidence for constitutive activation of the RET/PTC-RAS-BRAF signaling pathway in papillary thyroid carcinoma. Cancer Res 2003;63:1454-7.

30. Fagin JA. Challenging dogma in thyroid cancer molecular genetic-role of $R E T / P T C$ and $B R A F$ in tumor initiation. $\mathbf{J}$ Clin Endocrinol Metab 2004;89:4264-6.

31. Santoro M, Melillo M, Carlomagno F, Vecchio G, Fusco A. Minireview: RET: normal and abnormal functions. Endocrinology 2004; 145:5448-51.

32. Cheung L, Messina M, Gill A, Clarkson A, Learoyd D, Delbridge $L$, et al. Detection of the PAX8-PPAR $\gamma$ fusion oncogene in both follicular thyroid carcinomas and adenomas. J Clin Endocrinol Metab 2003;88:354-7.

33. Nikiforova MN, Lynch RA, Biddinger PW, Alexander EA, Dorn GW, Tallini G, et al. RAS point mutations and PAX8-PPAR rearrangement in thyroid tumors: evidence for distinct molecular pathways in thyroid follicular carcinoma. J Clin Endocrinol Metab 2003;88:2318-26.

34. Suarez HG. Genetic alterations in human epithelial tumors. Clin Endocrinol 1998;48:531-46.

35. Maciel RMB, Kimura ET, Cerutti JM. Patogênese dos tumores diferenciados da tireóide. Arq Bras Endocrinol Metab 2005;49:691-700.

36. Silva JE. Thyroid hormone control of thermogenesis and energy balance. Thyroid 1995;5:481-92.

37. St. Germain DL. Development effects of thyroid hormone: the role of deiodinases in regulatory control. Biochem Society Transactions 1999;27:83-8.

38. Wu Y, Koening RJ. Gene regulation by thyroid hormone. Trends Endocrinol Metab 2000;11:207-11.

39. St. Germain DL, Galton VA. The deiodinase family of selenoproteins. Thyroid 1997;7:655-68.

40. Kuiper GG, Kester MH, Peeters RP, Visser TJ. Biochemical mechanisms of thyroid hormone deiodination. Thyroid 2005; 15:787-98.

41. Salvatore D, Tu H, Harney JW, Larsen PR. Type 2 iodothyronine deiodinase is highly expressed in human thyroid. J Clin Invest 1996;98:962-8.

42. Ishii $H$, Inada $M$, Tanaka $K$, Mashio $Y$, Naito $K$, Nishikawa M, et al. Triiodothyronine generation from thyroxine in human thyroid: enhanced conversion in Graves' thyroid tissue. J Clin Endocrinol Metab 1981;52:1211-7. 
43. Köhrle J. Local activation and inactivation of thyroid hormones: the deiodinase family. Mol Cell Endocrinol 1999;151:103-19.

44. Maia AL, Kim BW, Huang SA, Harney JW, Larsen PR. Type 2 iodothyronine deiodinase is the major source of plasma T3 in euthyroid humans. J Clin Invest 2005;115:2524-33.

45. Visser TJ. Role of sulfation in thyroid hormone metabolism. Chem Biol Interact 1994;92:293-303.

46. Maia AL, Kieffer JD, Harney JW, Larsen PR. Effect of 3,5,3'-triiodothyronine (T3) administration on dio1 gene expression and $T_{3}$ metabolism in normal and type 1 deiodinase-deficient mice. Endocrinology 1995;136:4842-9.

47. Jakobs TC, Schmutzler C, Meissner J, Kohrle J. The promoter of the human type $15^{\prime}$-deiodinase gene-mapping of the transcription start site and identification of a $D R+4$ thyroid hormone-responsive element. Eur J Biochem 1997;247:8897.

48. Zhang C, Kim S, Harney JW, Larsen PR. Further characterization of thyroid hormone response elements in the human type 1 iodothyronine deiodinase gene. Endocrinology 1998;247:288-97.

49. Ishii $H$, Inada M, Tanaka K, Mashio $Y$, Naito K, Nishikawa M, et al. Induction of outer and inner ring monodeiodinases in human thyroid gland by thyrotropin. J Clin Endocrinol Metab 1983;57:500-5.

50. Toyoda N, Nishikawa M, Mori Y, Yoshimura M, Masaki $\mathrm{H}$ Gondou A, et al. Identification of a 27-kilodalton protein with the properties of type I iodothyronine $5^{\prime}$-deiodinase in human thyroid gland. J Clin Endocrinol Metab 1992;74:533-8.

51. Schrek R, Schnieders F, Schmutzler C, Khörle J. Retinoids stimulate type I iodothyronine $5^{\prime}$-deiodinase activity in human follicular thyroid carcinoma cell lines. J Clin Endocrinol Metab 1994:79:791-8.

52. Fagin JA. Molecular pathogenesis of tumors of thyroid follicular cells. In: Fagin JA (ed). Thyroid cancer. Boston: Kluwer Academic Publishers, 1998. pp. 59-83.

53. Pachucki J, Ambroziak M, Tanski J, Luczak J, Nauman J, Nauman A. Type I $5^{\prime}$-iodothyronine deiodinase activity and mRNA are remarkably reduced in renal clear cell carcinoma. J Endocrinol Invest 2001;24:253-61.

54. Sabatino L, lervasi G, Ferrazzi P, Francesconi D, Chopra IJ. A study of iodothyronine $5^{\prime}$-monodeiodinase activities in normal and pathological tissues in man and their comparison with activities in rat tissues. Life Sci 2000;68:191-202.

55. Wawrzynska L, Sakowicz A, Rudzinski P, Langfort R, Kurzyna $M$. The conversion of thyroxine to triiodothyronine in the lung: comparison of activity of type I iodothyronine $5^{\prime}$ deiodinase in lung cancer with peripheral lung tissues. Monaldi Arch Chest Dis 2003;59:140-5.

56. Dutkiewicz S, Witeska A, Nauman A. the deiodination of thyroxine to triiodothyronine in the testes of patients with prostate cancer. Int Urol Nephrol 1995;27:81-5.

57. Macejova D, Liska J, Brtko J. Mammary gland carcinomarelated increase of type I iodothyronine $5^{\prime}$-deiodinase activity in Sprague-Dawley rats. Gen Physiol Biophys 2001;20:293-302.

58. Aceves C, Gopainathrao G, Rajkumar L, Guzman R, Yang J Nandi S, et al. Deiodinase type I (D1) in $\mathbf{N}$-methyl-Nnitrosourea-induced rat mammary carcinomas: differential expression in early and late arising tumors. The Endocrine Society $84^{\text {th }}$ Annual Meeting, San Francisco, CA, 2002, p. 299 (Abstract).

59. Aceves C, Rojas-Huidobro R. Effect of suckling and adrenergic stimulation on peripheral deiodination in lactating rats: differential expression of type 1 deiodinases mRNA forms. $\mathbf{J}$ Endocrinol 2001;171:533-40.

60. García-Solís P, Aceves C. 5 'deiodinase in two breast cancer cell lines: effect of triiodothyronine, isoproterenol and retinoids. Mol Cell Endocrinol 2003;201:25-31.

61. Campos-Barros A, Hoell T, Musa A, Sampaolo S, Stoltenburg G, Pinna G, et al. Phenolic and tyrosil ring iodothyronine deiodination and thyroid hormone concentrations in the human central nervous system. J Clin Endocrinol Metab 1996;81:2179-85
62. Tannahill LA, Visser TJ, McCabe CJ, Kachilele S, Boelaert K, Sheppard Mc, et al. Dysregulation of iodothyronine deiodinase enzyme expression and function in human pituitary tumours. Clin Endocrinol 2002;56:735-43.

63. Baur A, Buchfelder M, Kohrle J. Expression of 5'-deiodinase enzymes in normal pituitaries and in various human pituitary adenomas. Eur J Endocrinol 2002;147:263-8.

64. Silva JE, Larsen PR. Comparison of iodothyronine 5'-deiodinase and other thyroid-hormone-dependent enzyme activities in the cerebral cortex of hypothyroid neonatal rat. Evidence for adaptation to hypothyroidism. J Clin Invest 1982;70:1110-23.

65. Burmeister LA, Pachucki J, St. Germain DL. Thyroid hormones inhibit type 2 iodothyronine deiodinase in the rat cerebral cortex by both pre-and posttranslational mechanisms. Endocrinology 1997;138:5231-7.

66. Gereben B, Salvatore D. Pretranslational regulation of type 2 deiodinase. Thyroid 2005; $15: 855-64$.

67. Kim BW, Daniels GH, Harrison BJ, Price A, Harney JW, Larsen $\mathrm{PR}$, et al. Overexpression of type 2 iodothyronine deiodinase in follicular carcinoma as cause of low circulating free thyroxine levels. J Clin Endocrinol Metab 2003;88:594-8.

68. Takano T, Miyauchi A, Ito $\mathrm{Y}$, Amino N. Thyroxine to triiodothyronine hyperconversion thyrotoxicosis in patients with large metastases of follicular thyroid carcinoma. Thyroid 2006;16:615-8.

69. Magrassi L, Butti G, Silini E, Bono F, Paoletti P, Milanesi G. The expression of genes of the steroid-thyroid hormone receptor superfamily in central nervous system tumors. Anticancer Res 1993:13:859-66.

70. Toms SA, Hercbergs A, Liu J, Kondo S, Barnett GH, Casey G, et al. Thyroid hormone depletion inhibits astrocytoma proliferation via a p53-independent induction of p21 (WAF/1CIP1). Anticancer Res 1998;18:289-94.

71. Murakami M, Araki O, Morimura T, Hosoi Y, Mizuma H, Yamada $M$, et al. Expression of type II iodothyronine deiodinase in brain tumors. J Clin Endocrinol Metab 2000;85:4403-6.

72. Nauman P, Bonicki W, Michalik R, Warzecha A, Czernicki Z. The concentration of thyroid hormones and activities of iodothyronine deiodinases are altered in human brain gliomas. Folia Neuropathol 2004;42:67-73.

73. Mori K, Yoshida K, Kayama T, Kaise N, Fukazama H, Kiso Y, et al. Thyroxine 5-deiodinase in human brain tumors. J Clin Endocrinol Metab 1993;77:1198-202.

74. Barrera-Hernandez G, Park KS, Dace A, Zhan Q, Cheng SY. Thyroid hormone-induced cell proliferation in GC cells is mediated by changes in G1 cyclin/cyclin-dependent kinase levels and activity. Endocrinology 1999;140:5267-74.

75. Stahl JH, Kendall SK, Brinkmeier ML, Greco TL, WatkinsChow DE, Campos-Barros A, et al. Thyroid hormone is essential for pituitary somatotropes and lactotropes. Endocrinology 1999;140:1884-92.

76. Canettieri G, Franchi A, Sibilla R, Guzman E, Centanni M. Functional characterization of the CRE/TATA box unit of type 2 deiodinase gene promoter in a human choriocarcinoma cell line. J Mol Endocrinol 2004;33:51-8.

77. Rihn B, Mohr S, McDowell SA, Binet S, Loubinox J, Galateau $\mathrm{F}$, et al. Differential gene expression in mesothelioma. FEBS Lett 2000;480:95-100.

78. Curcio C, Baqui MM, Salvatore D, Rihn BH, Mohr S, Harney $\mathrm{JW}$, et al. The human type 2 iodothyronine deiodinase is a selenoprotein highly expressed in a mesothelioma cell line. $\mathbf{J}$ Biol Biochem 2001;276:30183-7.

79. Morimura T, Tsunekawa K, Kasahara T, Seki K, Ogiwara T, Mori $M$, et al. Expression of type 2 iodothyronine deiodinase in human osteoblast is stimulated by thyrotropin. Endocrinology 2005;146:2077-84.

80. Huang SA, Dorfman DM, Genest DR, Salvatore D, Larsen PR. Type 3 iodothyronine deiodinase is highly expressed in the human uteroplacental unit and in fetal epithelium. J Clin Endocrinol 2003;88:1384-8.

81. Bates JM, St. Germain DL, Galton VA. Expression profiles of the three iodothyronine deiodinases, D1, D2, and D3, in developing rat. Endocrinology 1999;140:844-51. 
82. Slominski A, Wortsman J, Khon L, Ain KB, Venkataraman GM, Pisarchik A, et al. Expression of hypothalamic-pituitarythyroid axis related genes in the human skin. J Invest Dermatol 2002; 119:1449-55.

83. Kester MHA, Kuiper GGJM, Versteeg R, Visser T. Regulation of type III iodothyronine deiodinase expression in human cell lines. Endocrinology 2006;147:5845-54.

84. Baur A, Khorle J. Type 1 deiodinase is stimulated by iodothyronines and involved in thyroid hormone metabolism in human somatomammotroph GX cells. Eur J Endocrinol 1999; $140: 367-70$.

85. Huang SA, Tu HM, Harney JW, Venihaki M, Butte AJ, Kozakewich HPW, et al. Severe hypothyroidism caused by type 3 iodothyronine deiodinase in infantile hemangiomas. N Eng J Med 2000;343:185-9.

86. Huang SA, Fish SA, Dorfman DM, Salvatore D, Kozakewich HP, Mandel SJ, et al. A 21-year-old Woman with consumptive hypothyroidism due to a vascular tumor expressing type 3 iodothyronine deiodinase. J Clin Endocrinol Metab 2002;87:4457-46.
87. Huang A. Physiology and pathophysiology of type 3 deiodinase in humans. Thyroid 2005;15:875-81.

\section{Endereço para correspondência:}

Ana Luiza Maia

Setor de Tireóide, Serviço de Endocrinologia

Hospital de Clínicas de Porto Alegre

Rua Ramiro Barcelos 2350

90035-003 Porto Alegre, RS

Fax: (51) 3332-5188

E-mail: almaia@ufrgs.br 